Society \& Natural Resources

\title{
Interacting for the Environment: Engaging Goffman in Pro-Environmental Action
}

\section{Tom Hargreaves}

To cite this article: Tom Hargreaves (2016) Interacting for the Environment: Engaging Goffman in Pro-Environmental Action, Society \& Natural Resources, 29:1, 53-67

To link to this article: http://dx.doi.org/10.1080/08941920.2015.1054978

\section{(2) Published with license by Taylor \& Francis@ Tom Hargreaves}

\section{Published online: 27 Aug 2015.}

Submit your article to this journal

LII Article views: 171

Q View related articles $๘$

View Crossmark data $־$ 


\title{
Interacting for the Environment: Engaging Goffman in Pro-Environmental Action
}

\author{
TOM HARGREAVES \\ Science, Society and Sustainability (3S) Research Group, School of \\ Environmental Sciences, University of East Anglia, Norwich, \\ United Kingdom
}

\begin{abstract}
While there are profound disagreements about how more sustainable forms of living might be achieved, most research on pro-environmental action recognizes it as a fundamentally social challenge-demanding shifts not merely in individuals' attitudes and behaviors, but also in social norms, contexts, and practices. Despite the social nature of the challenge, perhaps the most fundamental social mediumsocial interaction-remains undertheorized in this area. To address this gap, this article applies Erving Goffman's understandings of social interaction to an ethnographic case study of a pro-environmental change initiative called Environment Champions. The analysis shows that social interaction plays a crucially important role in shaping responses to pro-environmental change processes, a role that has the potential to both help and hinder the spread of pro-environmental action. The article concludes by exploring how Goffman's ideas develop and extend current debates about pro-environmental behavior change.
\end{abstract}

Keywords banal environmentalism, conspicuous environmentalism, Erving Goffman, pro-environmental behavior, social interaction, social practice

The need to reduce the environmental burden of hitherto "normal" and unproblematic ways of life is becoming increasingly accepted. In recent years within UK policy, for example, a number of reports have addressed how behavior might be changed as part of a wider societal transition to a sustainable and low-carbon economy (e.g., Department of Environment, Food and Rural Affairs [DEFRA] 2008; Department of Energy and Climate Change [DECC] 2009; Dolan et al. 2010; House of Lords Select Committee on Science and Technology 2011). This has led to several initiatives to encourage pro-environmental actions, including: the ActOnCO2 campaign and carbon calculator to encourage individuals to reduce their carbon footprint, the Love Food Hate Waste initiative designed to reduce food waste (Waste and Resources

(C) Tom Hargreaves

This is an Open Access article. Non-commercial re-use, distribution, and reproduction in any medium, provided the original work is properly attributed, cited, and is not altered, transformed, or built upon in any way, is permitted. The moral rights of the named author(s) have been asserted.

Received 12 June 2014; accepted 17 February 2015.

Address correspondence to Tom Hargreaves, Science, Society and Sustainability (3S) Research Group, School of Environmental Sciences, University of East Anglia, Norwich NR4 7TJ, United Kingdom. E-mail: tom.hargreaves@uea.ac.uk 
Action Program [WRAP] 2015), and the Green Deal that aims to incentivize action to save energy in homes. The environmental social science that underpins these initiatives, however, presents a far from united voice. While some see a need to "work within" (Barr 2008, 261) the existing system, others call for more radical shifts in social systems and practices as the only appropriate response (e.g., Shove 2010; Shove, Pantzar, and Watson 2012). This article attempts to find something of a middle path between these two extremes. Despite their general agreement that some kind of broad social change is necessary, strangely, neither of these dominant approaches has, to date, paid much explicit or sustained (cf. Halkier 2013) attention to perhaps the most basic social medium: social interaction.

I aim to begin filling this gap by examining the role social interaction plays in attempts to reduce the environmental impacts of everyday actions. Drawing on evidence from an ethnographic case study of a pro-environmental change initiative called Environment Champions, the article draws on the work of Erving Goffmanperhaps the theorist par excellence of social interaction - to explore how some of the concepts he developed for the analysis of social interaction are also helpful in illuminating pro-environmental change processes.

The next section reviews existing social science research on pro-environmental action - that is, action deliberately aimed at reducing environmental impacts - which, despite moving increasingly toward collectively negotiated and contextually situated understandings, has so far neglected to focus explicitly on social interaction processes in any real depth. To address this, the work of Goffman, whose dramaturgical approach is presented as potentially helpful for examining how and why proenvironmental acts are or are not performed in specific times and places, is then introduced. Next, some of Goffman's ideas are applied to ethnographic evidence from the Environment Champions initiative. Finally, the article concludes by considering how Goffman's concepts help to develop and extend current debates about pro-environmental change processes.

\section{Pro-Environmental Action: Changing Behavior or Practice?}

Academic debate about how to reduce the environmental impacts of everyday actions has arguably settled into two opposing theoretical camps (Hitchings, Collins, and Day 2013). On one hand are those, predominantly environmental psychologists and behavioral economists, who understand the task of bringing about pro-environmental behavior as one of changing how individuals make behavioral decisions either by "nudging" them in particular directions (e.g., Thaler and Sunstein 2008) or by encouraging them to take up new pro-environmental attitudes or values (e.g., Xenias and Whitmarsh 2013). On the other hand, many environmental sociologists interpret the challenge as requiring broader changes to the social practices that make up normal everyday life (e.g., Røpke 2009; Shove 2010). The argument in this article, however, is that despite their profound differences and disagreements, these approaches share a common blind spot: social interaction.

Within environmental psychological approaches, the dominant aim has been to understand the relationships between pro- or anti-environmental attitudes or values, and everyday behavior. In attempting to overcome a persistent "value-action gap" (Blake 1999), researchers within this tradition have posited countless models, each identifying a different array of intermediary variables between attitudes and behavior (for an excellent review see Jackson 2005). An important aspect of this work has 
been to recognize that individuals behave with bounded rationality, and that they are influenced by their surrounding contexts in various ways. Different researchers have understood this context in different ways, however. Barr (2003), for example, refers to the impact of contextualized social norms on individuals' behaviors. Martin, Williams, and Clark (2006) refer to various practical "situational variables" as inhibiting pro-environmental decisions. Olli, Grendstad, and Wollebaek (2001), meanwhile, highlight social networks as vital in shaping pro-environmental attitudes and actions. Finally, within more recent work developed by behavioral economists, this surrounding context is understood as a "choice architecture" that influences particular decisions in various, and often unconscious, ways (e.g., Thaler and Sunstein 2008; Dolan et al. 2010). While these developments recognize that individuals do not make decisions in a social vacuum, it remains unclear within this body of work exactly how the surrounding context becomes internalized and embedded within an individual's thought and decision-making processes. Further, realization of the social nature of everyday action has also failed to challenge the long-standing assumption that pro-environmental behavior is the outcome of a process of ultimately individual decision-making (cf. Burgess et al. 2003).

By contrast, a more recent body of work led by environmental sociologists has turned attention away from individuals and their decision-making processes, to suggest that attempts to reduce the environmental burden of everyday activities should focus instead on the organization of social practices (e.g., Warde 2005; Røpke 2009; Shove 2010). As a leading exponent of this approach, Elizabeth Shove has argued that "patterns of consumption [and their associated impacts] follow from the routine accomplishment of what people take to be 'normal' ways of life" (Shove 2004, 117). Research attention should therefore be focused on what these normal social practices are made up of, and how over time they emerge, stabilize, evolve, and ultimately die out (Shove, Pantzar, and Watson 2012). Here, recent research has begun to focus on how social practices shape and coevolve with individuals' values, rather than resulting from them (Hards 2011), and on the difficulties individuals or even teams of individuals face in changing these socially embedded and historically established entities (Hargreaves 2011).

Shove (2010) suggests that "On all the counts that matter, social theories of practice on the one hand, and of behaviour on the other, are like chalk and cheese" (Shove 2010, 1279). Indeed, both approaches have been criticized, and often in equal and opposite ways. Where, for example, social psychological approaches are seen as too individualistic, too rationalist, and insufficiently critical of the status quo (e.g., Burgess et al. 2003), social practice approaches are seen as neglecting individual action, lacking explanatory and predictive capacity, and as too radical to generate useful policy prescriptions (see, e.g., the exchange between Shove $[2010 ; 2011]$ and Whitmarsh, O'Neill, and Lorenzoni [2011]). Nonetheless, despite their common moves away from socially isolated individuals as the key unit of analysis, both approaches have left forms of social interaction understudied and undertheorized.

For environmental psychologists and behavioral economists, irrespective of their focus on social norms and networks, the core objective has been and remains understanding individual's cognitive dispositions, and, as such, study of the interactions between multiple individuals has been ignored. Not only does this oversight risk ignoring a crucial vehicle by which attitudes, values, and norms may be exchanged, discussed, and learned, but it also neglects a crucial medium through which proenvironmental action is actively encouraged or discouraged in particular situations. Similarly, despite its emphasis on collective conventions (Shove 2003), social practice 
theory has, to date, tended to overlook the ways in which individual practitioners interact with one another when performing practices (cf. Røpke 2009; Halkier 2013). Here, more work is needed to examine how social interaction between practitioners may influence how practices are negotiated and performed in specific situations, how practices are transmitted from one practitioner to another (cf. Warde 2005), and, ultimately, how these processes shape the broader evolution and trajectory of particular practices.

The rest of this article begins to examine how social interaction processes are involved in and influence pro-environmental change processes - whether in behaviors or practices. To do this, it draws on the work of Erving Goffman, who, despite being one of the most widely celebrated and cited sociologists of the last century, has received only incidental and passing attention in the literature on pro-environmental action (e.g., Nye and Hargreaves 2010; Hards 2013). In this respect, the article serves to extend Brewster and Bell's (2009) call to develop a more "Environmental Goffman" by attending closely to how "the environment" is present (or absent) in everyday social interaction.

\section{Erving Goffman, Impression Management, and Frames}

Throughout his career, Goffman sought to understand the structure of the "interaction order" (Goffman 1983). In so doing, his work reminds readers that maintaining the appearance of a normal and competent individual in different situations, and thus avoiding various social sanctions, requires constant work. This work takes the form of a "skilled watchfulness" (Giddens 1991, 127), which, albeit often taken for granted, monitors each and every situation an individual may find themselves in, and decodes the relevant "social values or norms concerning involvement" (Goffman 1963b, 193), which in turn guide their actions. In unpacking the social situations in this way, Goffman devised numerous "mini-concepts" (Williams 1986), of which I highlight just two - impression management and frames - that appear especially helpful in understanding pro-environmental change processes.

In The Presentation of Self in Everyday Life (1959), Goffman explored how individuals comport themselves when interacting with others. Goffman observed that people reveal to, or conceal from, others certain information about themselves when interacting in order to give particular impressions. Through such impression management, people perform idealized versions of themselves to others, emphasizing how they meet or surpass social expectations. Crucially, the kinds of impressions people wish to create vary according to the situations they find themselves in because "what is proper in one situation may certainly not be proper in another" (Goffman 1963b, 12). Thus, by observing how people manage the impressions they give in different situations, it is possible to understand the specific social norms and expectations that hold in particular contexts. While impressions are constantly managed in this way, Goffman was also well aware that efforts at impression management are prone to failure and that, whatever impression they wish to give, people often unintentionally "give off" other less desirable impressions. To tackle these failed performances, Goffman describes various forms of "repair work" required to save face and avoid being discredited. The concept of "tact" is one such form of repair work in which, in shared situations, people help one another to overcome and avoid lapses (e.g., by ignoring or subtly correcting behavior that fails to meet situational demands).

The complementary concept of frames (Goffman 1974) provides a device through which the "norms concerning involvement" for different situations are effectively stored. A frame is a scheme of interpretation that enables people to understand, 
label and thus give meaning to particular situations. "When individuals attend to any current situation, they face the question: 'what is it that's going on here?"' (Goffman 1974, 8). The answer they arrive at represents the frame they have identified for that particular situation, and directs how they should interpret events and how they should accordingly behave. In Frame Analysis (1974), Goffman makes clear that any single strip of activity can potentially support multiple meanings. A wave of the hand, for example, might be interpreted as a hello or goodbye, an instruction to stop, an attempt to draw someone's attention to something, or even a manifestation of a nervous tic. As such, potentially awkward encounters might result from a simple misreading of the frame. Frames are thus powerful mechanisms of social control, and correct alignment with them is crucial to the ongoing accomplishment of everyday life,

The relevance of these concepts for understanding pro-environmental behavior or practice lies in the fact that in most contemporary social situations, individuals are not routinely expected to give the impression of being environmentally responsible to others. This suggests that if such a thing as a pro-environmental frame exists, it is only very rarely in play (cf. Evans 2011) due to a lack of "envirogenic environments" (Shove 2010) in contemporary everyday life. Indeed, as Hards (2013) argues regarding energy use, people actively hide or display their pro-environmental credentials in particular social situations in order to avoid excessive or radical proenvironmentalism becoming a source of social stigma (Goffman 1963b; Moisander and Pesonen 2002). This presents both a challenge and an opportunity for attempts to encourage pro-environmental action. The challenge is to examine how the dynamics of social interactions promote or inhibit pro-environmental acts in different situations. The opportunity is that such social dynamics might be used as powerful mechanisms through which pro-environmental action could be brought about.

\section{Pro-Environmental Interaction at Burnetts}

This section applies Goffman's concepts to an ethnographic case study of a proenvironmental behavior change initiative - called Environment Champions (EC) undertaken in the head offices of a British construction company named Burnetts. ${ }^{1}$ The EC program is run by the environmental charity Global Action Plan [GAP] (2015) and involves groups of employees trying to reduce their own and their colleagues' environmental impacts through a structured behavior change campaign. At Burnetts, a team of 16 volunteer Champions was recruited and, over the course of 11 months, they focused on reducing and recycling waste and saving energy around their offices. Practically, this involved a series of events being held, e-mails being sent, posters being put up, and audits and surveys being conducted, all designed to encourage pro-environmental action. Full details of the initiative are available in Hargreaves (2008).

An ethnographic approach was employed specifically to observe the processes through which pro-environmental changes unfold in specific contexts. The aim was to go beyond the abstract models and frameworks of attitude-behavior connection produced by environmental psychologists and to examine how they do (or do not) function on the ground. Similarly, in relation to social practice based studies, the aim was to explore in greater detail how practices are performed and negotiated in situ, and whether or not they are influenced by pro-environmental change initiatives. Nine months of participant observation was conducted during the EC initiative and involved attending all Champions team meetings, conducting a series of voluntary internships in different departments around the offices, and interviewing 38 employees, 
including all 16 Champions, other figures who were identified as important to the initiative, and several employees whom the initiative sought to influence.

In terms of environmental impacts, the EC initiative at Burnetts ultimately led to a $29 \%$ reduction (3.4 tonnes) reduction in waste sent to landfill, and a 5.6\% (6 tonnes $\mathrm{CO}_{2}$ ) reduction in electricity usage. These outcomes are relatively modest, even by comparison with EC initiatives run elsewhere (see Global Action Plan [GAP] 2006). Perhaps the most significant impact that the initiative had, however, was observed in changes to how employees around the offices interacted with one another and in how they approached previously routine tasks. It was these observations that inspired this article.

\section{Conspicuous Environmentalism: Responses to a Changed Situation}

During the initiative there were numerous occasions on which I observed employees at the offices make a conspicuous show of their pro-environmental thoughts or actions. This conspicuous environmentalism ( $c f$. Hards 2013) took many forms, but in each case it represented the bringing of environmental issues to the surface of daily activity where they had previously been ignored. Many of these occurrences were incidental and short-lived, but their pervasiveness and frequency suggest their significance.

The most obvious form of conspicuous environmentalism was seen in countless performances that indicated to others present that what was occurring should be seen in a pro-environmental light. On several occasions, I witnessed employees make gestures to others that indicated they were about to switch off a light in a room, or about to recycle a drinks can or plastic cup (Field Diary [FD], 93, 150, 169). For example, during my interview with David - one of the Champions - we were interrupted by a passer-by who said, "I couldn't understand why the lights weren't on, then I saw you're here David and I thought 'oh right' (laughs)" (David interview, 37). ${ }^{2}$

In this instance, the passer-by did not feel the need to explain his confusion. Instead, a simple "oh right" sufficed to communicate "you're trying to save energy," which explained why the lights were switched off.

Further, on several occasions, people who were aware of my interest in the EC initiative made displays of conspicuous environmentalism toward me. For instance, Sam made a point of saying "I'll turn the lights off in there then" (FD, 157) when leaving a room with me, and Paul commented "I didn't just drive to the coffee shop, I'd been somewhere else too" (FD, 169), when I saw him drive into the car parking lot moments after having seen him at a coffee shop that was a very short walk away.

Such occurrences did not involve only the volunteer Champions or those directly involved in the initiative, however. In interviews, several Champions described the emergence of "mini-Champions" (David interview, 39). For example, Craig described Elly as "quite an activist really within her department" (Craig interview, 19) because she regularly reminded her colleagues to recycle cans or switch off lights. Similarly, during participant observation in one office, Karen and Joanna took action against colleagues who were failing to use the newly installed recycling bins for plastic bottles:

At about 16:00 Karen came into the office and said: "It does apply to milk bottles, I'm going to send an email out." [she had just checked if you could recycle plastic milk bottles] The dialogue followed thus:

Joanna: Who was it who last made tea? Was it Rob? Rob when you made tea did you finish off a milk bottle? 
Rob: No.

Joanna: Good because if it'd been you you'd have been in big trouble.

Rob: No, I've been waiting to finish a milk bottle just so I can feel good about myself for using the new bin.

Nicola: Blimey, you're like the recycling police you lot. (FD, 183)

In a subsequent interview with Karen, I asked her about this incident and her response described what a "mini-Champion" does:

I think you heard me moaning about the plastic bottles, which is a permanent frustration of mine, because we use milk bottles in the kitchen and I must remove four milk bottles a week from the bin still. Even though people have been told about it... That's something I'm continually complaining about ... There's a bin, it's next to the main bin, so it's ridiculous really that they don't [use it]. (Karen interview, non-Champion, 7)

In a vein similar to writing on the "social inhibition of behavior" (e.g., Guerin 1989), the presence of these mini-Champions around the site further emphasized the messages of the Champions initiative, serving to create a new situation around everyday activity in which acting in pro-environmental ways came to be expected, and anti-environmental behavior became, in Karen's words, "ridiculous." In short, actions that would previously have been ignored suddenly became environmental flashpoints around the offices, as anyone could now be "picked up" (David interview, 23 ) in this way and asked to justify their actions.

Goffman (1963a) uses the concept of civil inattention to describe a key aspect of social order. Civil inattention is a learned performance found, for example, in the brief glances given to strangers in order to avoid walking into them but also to indicate there is no threat and that they may carry on as normal. During the EC initiative, something quite different seemed to be occurring. Acts that would previously have been accorded civil inattention, such as walking past the person at the photocopier, suddenly became opportunities to call others to account and potentially to apply a form of stigma to their actions. Goffman has been criticized for being a "nice-guy" theorist of social life (Billig 2001) who emphasized cooperation, stability, and continuity, rather than conflict, disruption, and change (Maines 1977). The EC initiative suggests, however, that his observations particularly around stigma can also help to explain change in the social situation. Where civil inattention engenders stability, by contrast, attempting to apply a stigma to particular actions may potentially bring about change. Following the initiative, a glance or a throwaway comment served effectively to emphasize that "things have changed and we should all fall into line with the new situation."

Despite the changed situation around the offices, it is certainly not the case that all attempted pro-environmental performances were successful. Some lapses in behavior might well be expected, but on several occasions during participant observation, people's claims to be behaving in line with the EC initiative's aims were let down by their observed actions. For example, "During my interview with Paul he tried to show me that all his documents were now double-sided, but the three or four examples he had on his desk were all single-sided" (FD, 150).

Paul had been trying to perform a degree of conspicuous environmentalism toward me during his interview, but the props of his performance told a different 
story. One reading of this observation is that, like those who persistently "forgot" to use the correct recycling bins or needed constant reminders to behave proenvironmentally from mini-Champions, Paul was trivializing and resisting the EC initiative by refusing to do what the Champions were asking. The fact that such attempted performances of conspicuous environmentalism were so pervasive around the site, however, suggests instead that the social situation at the offices had been changed by the EC initiative such that employees felt obliged to at least attempt to give pro-environmental impressions, even if their actions had not yet caught up. In Goffman's terms, while Paul attempted to fall into line with the new social situation, his alignment display (Goffman 1963a) was unsuccessful. The crucial point, however, is that neither Paul, nor others who might be interpreted as resisting or trivializing the EC initiative, could continue to get away with such flawed performances without risking being confronted and asked to justify the dissonance between their observed actions and the new environmentally charged atmosphere of the offices. In short, such failed alignment displays now carried the potential danger of generating a kind of anti-environmental stigma (Goffman 1963a; Hards 2013). Being caught leaving monitors on, or printing single-sided, was now a potential source of embarrassment or even something to feel guilty about, just as switching them off and printing double-sided had become a source of pride. The EC initiative thus appeared to have introduced a new social pressure to behave in a pro-environmental fashion that was exercised repeatedly and consistently reinforced through everyday interaction, even though, at times, practice was shown to be lagging behind rhetoric.

These observations suggest the emergence of a kind of socially shared "valueaction gap" (Blake 1999) in which "values" are seen as collectively held, rather than being solely properties of individuals, and are made present and negotiated through interactions in social situations. In this respect, a focus on forms of social interaction - and particularly on forms of impression management and associated alignment displays - is seen to extend the value-action gap beyond individual minds. In so doing, arguably, it may increase the significance of any discrepancy between espoused values and observed actions precisely because such dissonance was now a potential source stigma.

\section{Inconspicuous and Banal Environmentalism: Reframing the Offices}

The previous section showed that many of the effects of the EC initiative were conspicuous, occurring as noticeable pro-environmental interruptions to normal social interaction. In addition to these conspicuous acts, however, the Champions initiative also influenced how employees thought about and approached their own and others' practice in less visible ways. This section highlights the key forms of this inconspicuous environmentalism, and explores the extent to which the EC initiative brought about what Billig (1995) might call a banal environmentalism, or what Bell (2008) has called "virtual environmentalism," that is, one that is so embedded within the local surroundings as to go unnoticed, and indeed one that does not need to be noticed in order to be effective.

For many employees at Burnetts, much of the day was spent alone in an office individually getting on with work. While the previous section suggested that the presence of others helped to generate negotiation about and performances of pro-environmental action, these processes also occurred in the absence of others. Goffman's concept of frames (1974) is helpful in understanding these moments. 
Goffman is clear that frames are not created through interaction but are extrasituational, being manufactured and sustained in the wider sociocultural context (Goffman 1974, 1-2). Nonetheless, it is frames that help people to make sense of particular situations and to behave appropriately therein. Throughout the EC initiative, there were many examples, often recounted in interviews, of how the EC initiative had apparently influenced the framing of everyday work around the offices, causing employees to see and understand things differently, and thus to approach routine tasks in new ways. For example, as the following quotations illustrate, many employees explained how the EC initiative had made them stop, think, and rethink particular aspects of their daily routines:

I can't think exactly what it was now but it sort of made me stop and think of, you know, things that I could do to try and help [the environment]... just re-thinking things that you wouldn't necessarily think of doing otherwise. I mean I thought I was quite careful but just the silly things like turning my monitor off, I never thought of before. (Steph interview, non-Champion, 5)

Obviously I've seen a lot of the posters that go round and... I think that's quite good ... because I admit that I never used to recycle as much as what I do now because that's made me sort of stop and think about, like putting bottles in my bin. (Vicky interview, non-Champion, 5)

These quotes imply that the EC initiative had not only prompted employees to question their previously unquestioned acts, but also to arrive at new and environmentally relevant answers to the question "What is it that's going on here?" (Goffman 1974 , 8). In short, the EC initiative appeared to have given rise to new ways of interpreting particular tasks or instances around the offices as either pro- or anti-environmental. In Goffman's terms, the EC initiative appeared to have begun to generate a new, pro-environmental frame around the offices.

For members of the Champions team, this reframing process appeared to have been quite thoroughgoing, causing them not only to understand specific tasks in new ways, but to see the whole office through a new, pro-environmental frame. Melissa explained this as a generalized process of seeing things differently:

I must admit it's changed the way I see things, I mean I notice things more ... If I see something in a bin, that shouldn't be in there, then I'll say "That shouldn't be in there." But before I wouldn't even look in, near the bin... The bin's a bin, you know, and I'd stay away from it. (Melissa interview, 14)

David elaborated further, suggesting that the EC initiative had led to a process of attunement to pro-environmental action around the offices:

I worked in [a different office] for a couple of weeks, which is quite a big office, and there's certainly huge scope there for a similar [EC] scheme... having sort of become attuned to the best practice here it was very noticeable working there. (David interview, 8)

Both Melissa and David thus reflect on how, although the office did not undergo any physical changes, things began to appear differently, such that lights left on or 
waste in the wrong bin began to appear like warning beacons (Jelsma 2003) demanding their attention. The interaction process, here, is not between two humans but instead between humans and surrounding nonhuman artifacts (e.g., bins, lights, computer monitors, etc.). Beyond suggesting that nonhuman artifacts can form a part of recognizable "fronts" (Goffman 1959) - that is, as props within performances that convey a relatively fixed and socially recognizable meaning, such as a judge's wig or a dentist's chair - Goffman does not actively consider the roles that nonhumans may play in interaction processes. These observations add dynamism to the concept of "scripting" (e.g., Jelsma 2003), in which physical artifacts have particular possibilities for action designed into them at the point of production. Far from being embedded within artifacts themselves, it is shown here that scripts can be contested, negotiated, and rewritten if the surrounding social situation or "frame" itself is changed. At Burnetts, prior scripts-such as to ignore bins entirely-were seemingly being rewritten in ways that served to call proenvironmental frames to mind in specific situations and thus to prompt pro-environmental acts (cf. Hobson 2006).

The final form of this inconspicuous environmentalism that I highlight relates to the regular admission in interviews with employees around the site that they would now switch their colleagues' monitors or lights off "behind their backs." In other words, they would act pro-environmentally on behalf of their colleagues. Several of the non-Champions I spoke to mentioned having acted in this way. For example:

I've been in someone's office today and switched off two lights and their screen, because I knew they were out all morning and they hadn't done it. I would never have done that before. So, so erm but hopefully when they come back to their office, they've realized that someone's done that and they didn't do it themselves. (Steven interview, non-Champion, 5-6)

There are at least two interpretations of this kind of act. On the one hand, and most positively, these acts can be seen as a display of "tact" (Goffman 1959) in which employees were helping their colleagues to manage the impressions they give to others by engaging in face-saving acts. Seen as tact, these acts served to help others to avoid a flawed or failed performance of pro-environmentalism and thus to protect their reputations around the offices as good environmental stewards. ${ }^{3}$ On the other hand, and more negatively, these acts may be seen as attempts to send a subtle moral message to colleagues, particularly if they were perceived as resisting the Champions initiative, a message that reminds them that the social situation around the offices has changed and that they should now fall in line. Whichever interpretation is favored-and it is most likely that both were apparent at different times, depending on exactly whose pro-environmental lapses were being corrected - these observations provide further evidence that a new set of environmental standards were in place around the offices against which people could be evaluated and judged. In short, through the EC initiative, "the environment" appeared to have become a near-constant presence around the offices, sufficient to make people stop and change what they were doing, and to intervene in their colleagues' behavior in order to help them save face or to subtly remind them to align with the new pro-environmental frame around the offices or risk being discredited. 
This section has argued that, in addition to generating conspicuous forms of environmentalism, the EC initiative also had several inconspicuous impacts, causing employees to see things differently and approach tasks in new, pro-environmental ways. In Goffman's terms, such changes can be seen as the emergence of a new pro-environmental frame around the offices. At the same time, however, the crucial role played by physical artifacts in activating this frame at particular moments suggests there may be a need to extend Goffman's ideas. In particular, there is a need to understand how frames may become embedded within particular physical settings. Here, albeit developed in an altogether different context, I have found Billig's (1995) work on banal nationalism especially insightful.

Billig contends that arguments about nationalism and national identity surround all aspects of daily life. Where most theories of nationalism focus on what he calls hot nationalism, such as flag-waving parades, Billig suggests that cold or banal nationalism is in fact more pervasive and important. Such banal nationalism is found in the constant flaggings of national identity that are embedded in people's surroundings or in the ways they think and talk. Billig argues that the pervasiveness of these reminders is what prevents people forgetting their national identity, and ultimately serves to make it feel somehow natural.

In the EC initiative, the presence of what Billig might call hot environmentalism is immediately apparent in the various conspicuous performances and communal negotiations outlined in the previous section. Such events infrequently reminded employees to consider their environmental performance while at work. Following Billig, though, if this were the only effect of the initiative, such environmentalism might be forgotten once these events became fewer and further between. To some extent, the presence of the Champions team is designed to stop these events from disappearing, but even so, the Champions themselves have limited energy and multiple additional responsibilities, so it is very likely that that such hot environmentalism would eventually dwindle. In order for the EC initiative to generate durable change, therefore, the Champions needed to translate such hot environmentalism into banal environmentalism, and embed forgotten reminders and flaggings into the office environment. I would argue that the inconspicuous acts of environmentalism outlined in the preceding represent the beginnings of this process.

For the Champions, this began in processes of attunement and seeing things differently around the site. For these individuals, the office appeared to have taken on a new layer of meaning as flaggings of environmental issues began to appear in many aspects of office life, such as lights left on or waste in the wrong bin. A similar process occurred among the mini-Champions and those who were actively performing in pro-environmental ways by going round switching off their colleagues' electrical equipment, for example. Again, for these employees the office environment came to appear differently as environmental meanings were now embedded within it. For others, however, this process had barely begun, and regular hot reminders in the form of e-mails, posters, and reminders from colleagues appeared still to be required to assimilate environmental understandings into the office surroundings.

On the whole, however, the preceding sections have argued that a crucial change brought about by the EC initiative was not necessarily one of changing individual's attitudes, values, or beliefs or of fundamentally changing routine social practices, but of beginning to change the frame that underpinned much of everyday working life around the offices to one in which for most employees, in most situations and activities, "the environment" could no longer be ignored. 


\section{Discussion and Conclusions}

Despite the growing understanding of pro-environmental change processes as fundamentally social processes, the concept of social interaction has been routinely overlooked and, as such, remains drastically undertheorized in this area. To address this, this article has applied a range of concepts drawn from Erving Goffman's dramaturgical approach to social interaction to help analyze new empirical evidence from an ethnographic case study of a pro-environmental behavior change initiative undertaken in a workplace. Here, it was seen that a crucial aspect of the initiativeand one that would have been ignored by existing dominant approaches to pro-environmental change - was that it introduced new forms of social interaction to the offices - either as a form of conspicuous environmentalism as two or more employees would perform to one another and jointly negotiate their environmental acts, or as a more inconspicuous or even banal environmentalism in which individual employees were seen to change the way they approached particular tasks and interacted with their surrounding physical environment. These ideas are based on a single case study and, as such, further similar studies across more situations are needed before more robust conclusions can be drawn. Nonetheless, these observations suggest a number of ways in which ongoing debates about pro-environmental change processes might be developed and extended.

For environmental psychologists and behavioral economists, Goffman's concept of frames provides a key, and previously overlooked, dimension of social context that shapes individuals' attitudes, values, and behavior in important ways. Examining how people manage the impressions they give to others in order to align with particular frames, it is seen that the persistent "value-action gap" does not reside solely in the thoughts and minds of individuals but is instead socially shaped and shared. Together, these concepts reveal social interaction to be a crucial and, importantly, an observable arena in and through which social norms and individual values are collectively negotiated and either reinforced or challenged and changed. Although such norms and values do not always correlate directly with observed behaviors, social interaction is nonetheless revealed to play an important role in shaping the conditions of possible, or at least socially acceptable, action for individuals.

Goffman's concepts are similarly useful to extend ongoing debates within environmental sociology in relation to theories of social practice. Here, the focus on impression management and the alignment displays and exhibitions of tact it gives rise to provide a means of observing how both individual practitioners and communities of practice approach and collectively negotiate the practices they "carry" (Reckwitz 2002). In this way, social interaction helps to define a more explicitly active role for individual practitioners in shaping the future trajectory of practices than they are often afforded, and without the need to resort to methodological individualism. Further, and in contrast to much work on social practices that emphasizes their regular and routine reenactment, attending to specific and situated processes of social interaction demands a greater appreciation of variation across and variability within the performance of practices as practitioners are seen to align their performances with particular frames. While it is recognized that variation in performances does not necessarily translate into fundamental changes to practices themselves, it is also true that exploring how practitioners interact with one another when performing practices may provide important clues as to the future evolution of those practices. 
Taken together, these developments help to provide something of a bridge between the two currently opposed approaches to pro-environmental action outlined earlier. Social interaction offers a means of seeing how individuals actively influence their surrounding contexts and situations and the performance of practices that occur within them. At the same time, a focus on social interaction also illustrates very clearly how broader social structures - such as frames and the "norms concerning involvement" they contain-actively shape individuals' practical performances from one moment to the next. In short, focusing on interaction processes helps to blur the boundary between individuals and their surroundings, forcing analysis to concentrate on the "social individuals" that are both the product and producers of their sociomaterial context. Such a development, if it is more generally accepted, may open the door to more nuanced and interdisciplinary conversations capable of responding to the pressing need for more pro-environmental action.

\section{Acknowledgments}

Thanks to Professor Jacquelin Burgess and Dr Gill Seyfang, who supervised my PhD thesis, and for the valuable comments of three anonymous reviewers.

\section{Funding}

This research was conducted as part of my PhD thesis, funded by the UK Economic and Social Research Council (ESRC-PTA-031-2004-00291). I am also grateful to the ESRC for funding a postdoctoral research fellowship that has enabled me to publish this research more widely (PTA-026-27-2086).

\section{Notes}

1. To preserve the anonymity of participants, Burnetts and all participants' names used in this article are pseudonyms.

2. All quotations are drawn from interviews with members of the Champions team unless otherwise stated.

3. I thank an anonymous reviewer for this interpretation.

\section{References}

Barr, S. 2003. Strategies for sustainability: Citizens and responsible environmental behaviour. Area 35(3):227-40. doi: 10.1111/1475-4762.00172

Barr, S. 2008. Environment and society: Sustainability, policy and the citizen. Aldershot, UK: Ashgate.

Bell, M. M. 2008. An invitation to environmental sociology, 3rd ed. Los Angeles, CA: Pine Forge Press.

Billig, M. 1995. Banal nationalism. London, UK: Sage.

Billig, M. 2001. Humour and embarrassment: Limits of 'nice-guy' theories of social life. Theory, Culture \& Society 18 (5):23-43. doi:10.1177/02632760122051959

Blake, J. 1999. Overcoming the 'value-action gap' in environmental policy: Tensions between national policy and local experience. Local Environment 4(3):257-78. doi: 10.1080/ 13549839908725599

Brewster, B. H., and M. M. Bell. 2009. The environmental Goffman: Toward an environmental sociology of everyday life. Society \& Natural Resources 23(1):45-57. doi: 10.1080/ 08941920802653505 
Burgess, J., T. Bedford, K. Hobson, G. Davies, and C. Harrison. 2003. (Un)sustainable consumption. In Negotiating environmental change: New perspectives from social science, ed. F. Berkhout, M. Leach and I. Scoones, 261-92. Cheltenham, UK: Edward Elgar.

Department of Energy and Climate Change. 2009. The UK low carbon transition plan: National strategy for climate and energy. London, UK: Department of Energy and Climate Change.

Department of Environment, Food, and Rural Affairs. 2008. A framework for pro-environmental behaviours. London, UK: Department of Environment, Food and Rural Affairs.

Dolan, P., D. Halpern, K. Hallsworth, D. King, and I. Vlaev. 2010. MINDSP ACE: Influencing behaviour through public policy. London, UK: Institute for Government for the Cabinet Office.

Evans, D. 2011. Consuming conventions: Sustainable consumption, ecological citizenship and the worlds of worth. Journal of Rural Studies 27(2):109-15. doi: 10.1016/j.jrurstud.2011. 02.002

Giddens, A. 1991. Modernity and self-identity: Self and society in the late modern age. Cambridge, UK: Polity.

Global Action Plan (GAP). 2006. Changing environmental behaviour: A review of the evidence for behaviour change from Global Action Plan. London, UK: Global Action Plan.

Global Action Plan. 2015. Global Action Plan website. http://www.globalactionplan.org.uk (accessed May 13, 2015).

Goffman, E. 1959. The presentation of self in everyday life. London, UK: Penguin Books.

Goffman, E. 1963a. Behavior in public places: Notes on the social organisation of gatherings. New York, NY: Free Press.

Goffman, E. 1963b. Stigma: Notes on the management of spoiled identity. London, UK: Penguin Books.

Goffman, E. 1974. Frame analysis: An essay on the organization of experience. Boston, MA: Northeastern University Press.

Goffman, E. 1983. The interaction order: American Sociological Association, 1982 presidential address. American Sociological Review 48:1-17. doi: 10.2307/2095141

Guerin, B. 1989. Social inhibition of behavior. Journal of Social Psychology 129(2):225-33. doi: $10.1080 / 00224545.1989 .9711723$

Halkier, B. 2013. Methodological consequences of integrating concepts of social interaction in practice theoretical approaches. Paper presented at From Practice Turn to Praxeological Mainstream Conference, Vienna, Austria, June 6-7.

Hards, S. 2011. Social practice and the evolution of environmental values. Environmental Values 20:23-42. doi: 10.3197/096327111x12922350165996

Hards, S. K. 2013. Status, stigma and energy practices in the home. Local Environment 18(4):438-54. doi: 10.1080/13549839.2012.748731

Hargreaves, T. 2008. Making pro-environmental behaviour work: An ethnographic case study of practice, process and power in the workplace. Unpublished $\mathrm{PhD}$ thesis, University of East Anglia, Norwich, UK.

Hargreaves, T. 2011. Practice-ing behaviour change: Applying social practice theory to pro-environmental behaviour change. Journal of Consumer Culture 11(1):79-99. doi: $10.1177 / 1469540510390500$

Hitchings, R., R. Collins, and R. Day. 2013. Inadvertent environmentalism and the actionvalue opportunity: Reflections from studies at both ends of the generational spectrum. Local Environment 20(3):369-85. doi: 10.1080/13549839.2013.852524

Hobson, K. 2006. Bins, bulbs, and shower timers: On the 'techno-ethics' of sustainable living. Ethics, Place \& Environment 9(3):317-36. doi: 10.1080/13668790600902375

House of Lords Select Committee on Science, and Technology. 2011. Behaviour change: 2nd report of session 2010-12. London, UK: HMSO. 
Jackson, T. 2005. Motivating sustainable consumption: A review of evidence on consumer behaviour and behavioural change. Centre for Environmental Strategy, University of Surrey, Guildford, Surrey, United Kingdom.

Jelsma, J. 2003. Innovating for sustainability: Involving users, politics and technology. Innovation 16(2):103-16. doi: 10.1080/13511610304520

Maines, D. R. 1977. Social organization and social structure in symbolic interactionist thought. Annual Review of Sociology 3:235-59. doi: 10.1146/annurev.so.03.080177. 001315

Martin, M., I. D. Williams, and M. Clark. 2006. Social, cultural and structural influences on household waste recycling: A case study. Resources, Conservation and Recycling 48(4):357-95. doi: 10.1016/j.resconrec.2005.09.005

Moisander, J., and S. Pesonen. 2002. Narratives of sustainable ways of living: Constructing the self and the other as a green consumer. Management Decision 40(4):329-42. doi: $10.1108 / 00251740210426321$

Nye, M., and T. Hargreaves. 2010. Exploring the social dynamics of pro-environmental behavior change. Journal of Industrial Ecology 14(1):137-49. doi: 10.1111/j.1530-9290. 2009.00193.x

Olli, E., G. Grendstad, and D. Wollebaek. 2001. Correlates of environmental behaviors: Bringing back social context. Environment and Behavior 33(2):181-208. doi: 10.1177/ 0013916501332002

Reckwitz, A. 2002. The status of the "material" in theories of culture: From "social structure" to "artefacts". Journal for the Theory of Social Behaviour 32(2):195-217. doi: 10.1111/ $1468-5914.00183$

Røpke, I. 2009. Theories of practice-New inspiration for ecological economic studies on consumption. Ecological Economics 68:2490-97. doi: 10.1016/j.ecolecon.2009.05.015

Shove, E. 2003. Comfort, cleanliness and convenience: The social organization of normality. Oxford, UK: Berg.

Shove, E. 2004. Changing human behaviour and lifestyle: A challenge for sustainable consumption. In The ecological economics of consumption, ed. L. Reisch and I. Røpke, 111-31. Cheltenham, UK: Edward Elgar.

Shove, E. 2010. Beyond the ABC: Climate change policy and theories of social change. Environment and Planning A 42:1273-85. doi: 10.1068/a42282

Shove, E. 2011. On the difference between chalk and cheese-A response to Whitmarsh et al's comments on "Beyond the ABC: Climate change policy and theories of social change". Environment and Planning A 43:262-64. doi: 10.1068/a43484

Shove, E., M. Pantzar, and M. Watson. 2012. The dynamics of social practice: Everyday life and how it changes. London, UK: Sage.

Thaler, R. H., and C. R. Sunstein. 2008. Nudge: Improving decisions about health, wealth and happiness. London, UK: Penguin.

Warde, A. 2005. Consumption and theories of practice. Journal of Consumer Culture 5(2):131-53. doi: $10.1177 / 1469540505053090$

Waste, and Resources Action Program. 2015. Love food hate waste. http://www.lovefood hatewaste.com (accessed May 13, 2015).

Whitmarsh, L., S. O'Neill, and I. Lorenzoni. 2011. Climate change or social change? Debate within, amongst, and beyond disciplines. Environment and Planning A 43:258-61. doi: $10.1068 / \mathrm{a} 43359$

Williams, S. J. 1986. Appraising Goffman. British Journal of Sociology 37(3):348-69. doi: $10.2307 / 590645$

Xenias, D., and L. Whitmarsh. 2013. Dimensions and determinants of expert and public attitudes to sustainable transport policies and technologies. Transportation Research Part A: Policy and Practice 48:75-85. doi: 10.1016/j.tra.2012.10.007 